\title{
Evaluation of Chemical Analysis Method and Determination of Polycyclic Aromatic Hydrocarbons Content from Seafood and Dairy Products
}

\author{
So-Young Lee ${ }^{1}$, Jee-Yeon Lee ${ }^{2}$ and Han-Seung Shin ${ }^{1}$ \\ ${ }^{1}$ Department of Food Science and Biotechnology and Food and Bio Safety Research Center, Dongguk University Seoul, Seoul, Korea \\ ${ }^{2}$ Nutrition Policy \& Promotion Team, Korea Health Industry Development Institute, Chungcheongbuk-do, Korea
}

(Received August 9, 2015; Revised September 20, 2015; Accepted September 23, 2015)

\begin{abstract}
This study was carried out to investigate contents of 8 polycyclic aromatic hydrocarbons (PAHs) from frequently consumed seafood and dairy products and to evaluate their chemical analysis methods. Samples were collected from markets of 9 cities in Korea chosen as the population reference and evaluated. The methodology involved saponification, extraction with n-hexane, clean-up on Sep-Pak silica cartridges and gas chromatograph-mass spectrometry analysis. Validation proceeded on 2 matrices. Recoveries for 8 PAHs ranged from 86.87 to $103.57 \%$. The limit of detection (LOD) 8 PAHs was $0.04 \sim 0.20 \mu \mathrm{g} / \mathrm{kg}$, and limit of quantification (LOQ) of 8 PAHs was $0.12 \sim 0.60 \mu \mathrm{g} / \mathrm{kg}$. The mean concentration of benzo[a]pyrene (BaP) was $0.34 \mu \mathrm{g} / \mathrm{kg}$ from seafood and $0.34 \mu \mathrm{g} / \mathrm{kg}$ from dairy products. The total PAHs concentration was $1.06 \mu \mathrm{g} / \mathrm{kg}$ in seafood and $1.52 \mu \mathrm{g} / \mathrm{kg}$ in dairy products.
\end{abstract}

Key words: Polycyclic aromatic hydrocarbon, Seafood, Dairy products, Carcinogen

\section{INTRODUCTION}

Polycyclic aromatic hydrocarbons (PAHs) constitute a class of carcinogenic and mutagenic organic compounds based on two or more aromatic rings and belonging to the Food and Environment Contaminants $(1,2)$.

The International Agency of Research on Cancer classification of benzo[a]pyrene $(\mathrm{BaP})$ was changed from group 2A (probably carcinogenic to humans) to group 1 (carcinogenic to humans), chrysene (CHR) was changed from group3 (not classifiable for humans) to group 2B (possibly carcinogenic to humans), and benzo[a]anthracene (BaA) was re-grouped from $2 \mathrm{~A}$ to $2 \mathrm{~B}(3,4)$. According to the EU Scientific Committee on Food (SCF), BaP can be used as a marker for the occurrence and effect of carcinogenic PAHs in food. Maximum levels of BaP in a range of foodstuffs are now specified in a Commission Regulation (Regulation EC No 1881/2006) (5). However, the European Food Safety Authority in $2008(6,7)$ concluded that $\mathrm{BaP}$ is not a suitable

Correspondence to: Han-Seung Shin, Department of Food Science and Biotechnology and Food and Bio Safety Research Center, Dongguk University Seoul, Seoul 04620, Korea E-mail: spartan@dongguk.edu

This is an Open-Access article distributed under the terms of the Creative Commons Attribution Non-Commercial License (http:// creativecommons.org/licenses/by-nc/3.0) which permits unrestricted non-commercial use, distribution, and reproduction in any medium, provided the original work is properly cited. indicator for the occurrence of PAHs in food, and that $4 \mathrm{PAH}$ subgroup (the sum of $\mathrm{BaA}$, chrysene (CHR), benzo[b]fluoranthene $(\mathrm{BbF})$ and $\mathrm{BaP})$ and 8 PAHs subgroup (the sum of $\mathrm{BaA}, \mathrm{CHR}, \mathrm{BaF}$, benzo[k]fluoranthene $(\mathrm{BkF}), \mathrm{BaP}$, dibenzo[a,h]anthracene (DahA), benzo[g,h,i]perylene (BghiP), and indeno[1,2,3-c,d]pyrene (IcdP)) should be used (8).

They are formed at high temperatures in natural processes (fires, volcanic eruptions, etc.) and in anthropogenic processes (burning of fossil fuels, vehicles emissions, plants of petroleum processing, etc.) due to the incomplete combustion of organic matter. PAHs are largely known as ubiquitous environmental contaminants due to their ability to be sorbed onto atmospheric particulate matter and become transported all over the planet (9). Soils, surface waters, and sediments may be contaminated by PAHs due to atmospheric fallout, urban runoff, deposition from sewage, and by oil or gasoline spills. Hence, there is a potential for ingredients like food crops to become environmentally contaminated as a result (10).

In fact, the main source of exposure to PAHs for nonsmokers and non-occupationally-exposed adults is food. Diet contributes to more than $90 \%$ of total PAHs exposures of the general population in various countries (11).

Foods of animal origin are recognized as one of the main PAHs givers being fatty foods such as eggs or dairy products like whole milk, yoghourt, butter, or cheese. Especially, the presence in cow's milk is probably due to the feeding of dairy cattle in grass and soil polluted with air- 
borne PAHs.

Also, these PAHs are easily accumulated in fish and shellfish, especially by bivalve mollusc like clams, oysters, mussels and scallops, species that are exposed to various kind of PAHs following oil spills at ocean and be contaminated as a result $(10,12)$. And seafood can be contaminated by the marine food web. Concentration of $\mathrm{BaP}$ and other PAHs can be various in fish based on the source and preparation of fish.

Due to stable structure and lipophilic character of PAHs, they are apt to concentrate and intensify in the food chain notably related to fat. However, a few regulations of the maximum allowable levels for PAHs in dairy products and seafood have been established (12). European Union has stressed and recommended that PAHs to be measured in as wide as possible in food products in order to obtain result on the occurrence and specific concentrations in a various matrices (13). Therefore, dairy products and marine products being upper predators require monitoring and regulations about them should be set based on this study.

\section{MATERIALS AND METHODS}

Chemicals and materials. The 8 PAHs used in this study were $\mathrm{BaA}, \mathrm{CHR}, \mathrm{BbF}, \mathrm{BkF}, \mathrm{BaP}, \mathrm{DahA}, \mathrm{BghiP}$, and IcdP supplied as individual stock solutions by Supelco (Bellefonte, PA, USA). And CHR-d12, BaP-d12 (obtained from Supelco) were used as an internal standard. All solvents (dichloromethane, ethyl alcohol, methanol, and nhexane) were of HPLC grade and were purchased from Burdick \& Jackson (Muskegon, MI, USA). Water was purified by a Milli-Q water purification system (Billerica, MA, USA). Sodium sulfate $\left(\mathrm{Na}_{2} \mathrm{SO}_{4}\right.$, minimum $99 \%$ purity) used for dehydration and potassium hydroxide $(\mathrm{KOH}$, minimum $85 \%$ purity) used for saponification were obtained from Junsei (Chuo-ku, Tokyo, Japan). Sep-Pak Silica cartridges, supplied by Waters (Milford, MA, USA), were used as solid phase extraction for purification. PTFE membrane filters ( $25 \mathrm{~mm}, 0.45 \mu \mathrm{m})$ were purchased from Agela Technologies (Wilmington, DE, USA).

Sample preparation. Food samples were collected from September 2014 to March 2015, in 18 large supermarkets located in 9 cities, Korea. Samples were homogenized in a blender and stored in a freezer at $-20^{\circ} \mathrm{C}$ in tightly sealed bottles prior to extraction and analysis. Foods samples were classified under two groups. The first group included 15 samples of seafood. The second group included 15 samples of dairy products.

Extraction and clean-up. A $10 \mathrm{~g}$ of the homogenized sample was weighed into a round bottom flask $(300 \mathrm{~mL})$, spiked with $1 \mathrm{~mL}$ of deuterated internal standard $(100 \mu \mathrm{g} /$ kg CHR-d12, BaP-d12. A $100 \mathrm{~mL}$ of $1 \mathrm{M}$ potassium hydrox- ide (Junsei) in ethanol (Burdick \& Jackson) was added for alkaline degradation under reflux at $80^{\circ} \mathrm{C}$ for $3 \mathrm{hrs}$ to isolate PAHs bound to the sample and to eliminate the matrix that would interrupt the PAH analysis. After cooling the flask with cold water, pre-weighed amount of n-hexane (50 mL) (Burdick \& Jackson) and 1:1 ethanol/n-hexane $(50 \mathrm{~mL})$ (Burdick \& Jackson) were added. Then the solution was filtered through filter paper (Filter paper $110 \mathrm{~mm}$; Advantec, Toyo Roshi Kaisha, Ltd., Japan) and transferred to a separating funnel. This solution was liquid-liquid extracted two times with $50 \mathrm{~mL}$ n-hexane (Burdick \& Jackson), after washes three times with $50 \mathrm{~mL}$ of distilled water (Milli-Q water purification system). The clear upper hexane layer was dried using anhydrous sodium sulfate (Junsei) and collected into a round bottom flask $(250 \mathrm{~mL})$. The extracts were reduced to a small volume using a rotary evaporator (Rotary vacuum evaporator N-N series SB-100; EYELA, Tokyo, Japan) at $37^{\circ} \mathrm{C}$. The extract contains not only PAHs, but also numerous other hydrophobic and slightly non polar compounds. These components must be removed in further steps of analysis in order to facilitate the separation and quantification of single PAHs. Samples were first eluted using an activated solid phase extraction cartridge (Sep-Pak Silica cartridges, Waters) with a $5 \mathrm{~mL}$ of n-hexane (Burdick \& Jackson) and mixture of $15 \mathrm{~mL} \mathrm{n-}$ hexane-dichloromethane (3:1) (Burdick \& Jackson). This resulting solution was taken up to dryness using a gentle stream of nitrogen gas at $37^{\circ} \mathrm{C}$, re-dissolved in $1 \mathrm{~mL}$ of dichloromethane (Burdick \& Jackson). The solution was passed through a $0.45 \mu \mathrm{m}$ PTFE membrane filter (Agela Technologies) and transferred to $2 \mathrm{~mL}$ amber screw-cap vials (Agilent Technologies,USA). An aliquot of $1 \mu \mathrm{L}$ of this solution was injected into the GC/MS system Agilent Technologies 7820A/5975 MSD GC-MS apparatus (Santa Clara, CA).

GC-MS analysis of PAHs. The sample extracts were analyzed using an Agilent Technologies 7820A/5975 MSD GC- MS apparatus (Santa Clara, CA) with the conditions listed in Table 1. The used column is a HP-5MS column $(30 \mathrm{~m} \times 0.25 \mathrm{~mm}$, ID particle size $0.25 \mu \mathrm{m})$. Ultra pure $(99.999 \%)$ helium is used as a carrier gas $(1.0 \mathrm{~mL} / \mathrm{min})$. The solutions of the extracted are injected in the splitless mode. The mass spectrometer was operated in the electron ionization (EI) mode using selected ion monitoring (SIM). Typically, two to four ions are monitored per compound, target ions were 228, 252, 276, 278, 240 (IS), and 264 (IS) for the 8 PAHs. The list of analyzed compounds and internal standards employed, the quantification ion and the confirmation ion are shown in Table 2.

Identification and quantification of PAHs. The identification of individual PAH was performed by comparison of the substance retention time and their retention time 
Table 1. Analysis conditions of gas chromatography-mass spectroscopy for the eight polycyclic aromatic hydrocarbons

\begin{tabular}{ll}
\hline \hline Instrument & Agilent Technologies 689ON/5975 MSD \\
Column & HP-5MS $30 \mathrm{~m} 0.25 \mathrm{~mm}$ ID $0.25 \mu \mathrm{m}$ \\
Column oven temperature & $80(1 \mathrm{~min}) \rightarrow 245(6 / \mathrm{min}) \rightarrow 270(30 / \mathrm{min}$, hold $10 \mathrm{~min}) \rightarrow 310(10 \mathrm{~min}$, post run $)$ \\
Carrier gas & Helium $(1.0 \mathrm{~mL} / \mathrm{min})$ \\
Injection volume and temperature & $1.0 \mu \mathrm{L}($ Splitless $), 270$ \\
MS source temperature/MS quadrupole temperature & $230 / 150$ \\
MS mode & $\mathrm{SIM}$ \\
\hline
\end{tabular}

Table 2. List of 8 PAHs, the deuterated standards employed (underlined), the quantification ion and confirmation ion for SIM (single ion monitoring) GC-MS mode

\begin{tabular}{|c|c|c|c|c|c|c|c|c|c|c|}
\hline Chemical & $\mathrm{BaA}$ & $\mathrm{CHR}$ & $\mathrm{BbF}$ & $\mathrm{BkF}$ & $\mathrm{BaP}$ & BghiP & IcdP & DahA & BaP-d12 & CHR-d12 \\
\hline Qunatification ion & 228 & 228 & 252 & 252 & 252 & 276 & 276 & 278 & 264 & 240 \\
\hline Confirmation ion & 226,229 & 226,229 & 250,253 & 250,253 & 250,253 & 274,277 & 276,277 & 276,279 & 263,265 & 236,241 \\
\hline
\end{tabular}

obtained with true standards in the same conditions. The way to prove the identification of the PAHs is molecular mass or characteristic mass fragments using a library database. To obtain standard calibration curves, PAH standard solutions relative to the two internal standard compounds were determined at five PAHs concentrations $(1,2,5,10$, and $20 \mu \mathrm{g} / \mathrm{kg}$ ). For validation of recovery, all standards containing $100 \mu \mathrm{g} / \mathrm{kg}$ of CHR-d12 and BAP-d12 as an internal standard.

Method validation and analytical quality assurance. Method was validated for accuracy, precision, linearity, limit of detection (LOD) and limit of quantification (LOQ). Validation proceeded on 2 matrices including seafood and dairy product. All standard mixtures were injected at a volume of $1 \mu \mathrm{L}$ in triplicate to construct calibration curves. Accuracy (\%) and precision (\%) were evaluated by repeating the spiked samples run. The spiked samples were analyzed in 3 times during the same day (intra days) and in three different days (inter days).

\section{RESULTS AND DISCUSSION}

Linearity of the calibration curve. The chromatograms of the 8 PAHs in the standards and samples are shown in Fig. 1. The PAHs showed a wide spectrum and all 8 PAHs behaveed the same in the standard and the sample. The recoveries were obtained using an internal standard method, assuming that PAHs and d-PAHs appear to behave in a similar during extraction. For calibration curves, the response factors of PAHs relative to the two internal standard were assessed at five different PAH concentration levels $(1,2,5,10$, and $20 \mu \mathrm{g} / \mathrm{kg})$. The squared correlation coefficient of determination $\left(\mathrm{R}^{2}\right)$ measures the chromatographic area as the concentration of the calibration curve. The correlation coefficient was observed for PAHs at all concentrations with $\mathrm{R}^{2}>0.99$.
LOD and LOQ. LOD is defined as the lowest concentration leading to a signal-to-noise ratio of 3 whereas the LOQ is defined as the concentration leading to a signal-to-noise ratio of 10. The LOD of seafood matrix was $0.12 \sim 0.20 \mu \mathrm{g} /$ $\mathrm{kg}$, and the LOQ was $0.36 \sim 0.60 \mu \mathrm{g} / \mathrm{kg}$. The LOD of dairy product matrix was $0.04 \sim 0.20 \mu \mathrm{g} / \mathrm{kg}$, and the LOQ was $0.12 \sim 0.60 \mu \mathrm{g} / \mathrm{kg}$ (Table 3).

Recovery. The recovery values were measured using the peak area of CHR-d12 and BaP-d12. Average recovery varied between $90.99 \sim 103.57 \%$ from seafood matrix and $90.43 \sim 102.67 \%$ from dairy product matrix. And average relative standard deviation was $8.08 \sim 15.31 \%$ and $6.75 \sim$ $13.26 \%$, respectively (Table 3 ).

Accuracy (\%) and precision (\%) analysis. Accuracy $(\%)$ and precision (\%) were performed for at 5 concentrations. Intra-day accuracy and precision were evaluated by analyzing one sample on 3 different days. Inter-day accuracy and precision were performed by running tree analyses on the same day under the same conditions. Results are presented in Table 4.

PAH content in seafood and dairy products. The concentration of the 8 PAHs in seafood and dairy products were determined. GC-MS chromatograms of the 8 PAHs for the standards and spiked samples are given in Fig. 1. The concentrations of the 8 PAHs in 15 samples of seafood are presented in Table 5, then 21 samples of dairy products are presented in Table 6. All of the experiments were carried out in triplicate. As seen in Table 5, BghiP were not detected in all seafood samples. The mean concentration of $\mathrm{BaP}$ in seafood samples was $0.34 \mu \mathrm{g} / \mathrm{kg}, 4$ PAHs were presented at $0.67 \mu \mathrm{g} / \mathrm{kg}$, and the total concentration of 8 PAHs was $1.06 \mu \mathrm{g} / \mathrm{kg}$. The mean concentration of BaP in dairy product samples was $0.34 \mu \mathrm{g} / \mathrm{kg}$, 4 PAHs were presented at $1.02 \mu \mathrm{g} /$ $\mathrm{kg}$, and the total concentration of 8 PAHs was $1.52 \mu \mathrm{g} / \mathrm{kg}$, 

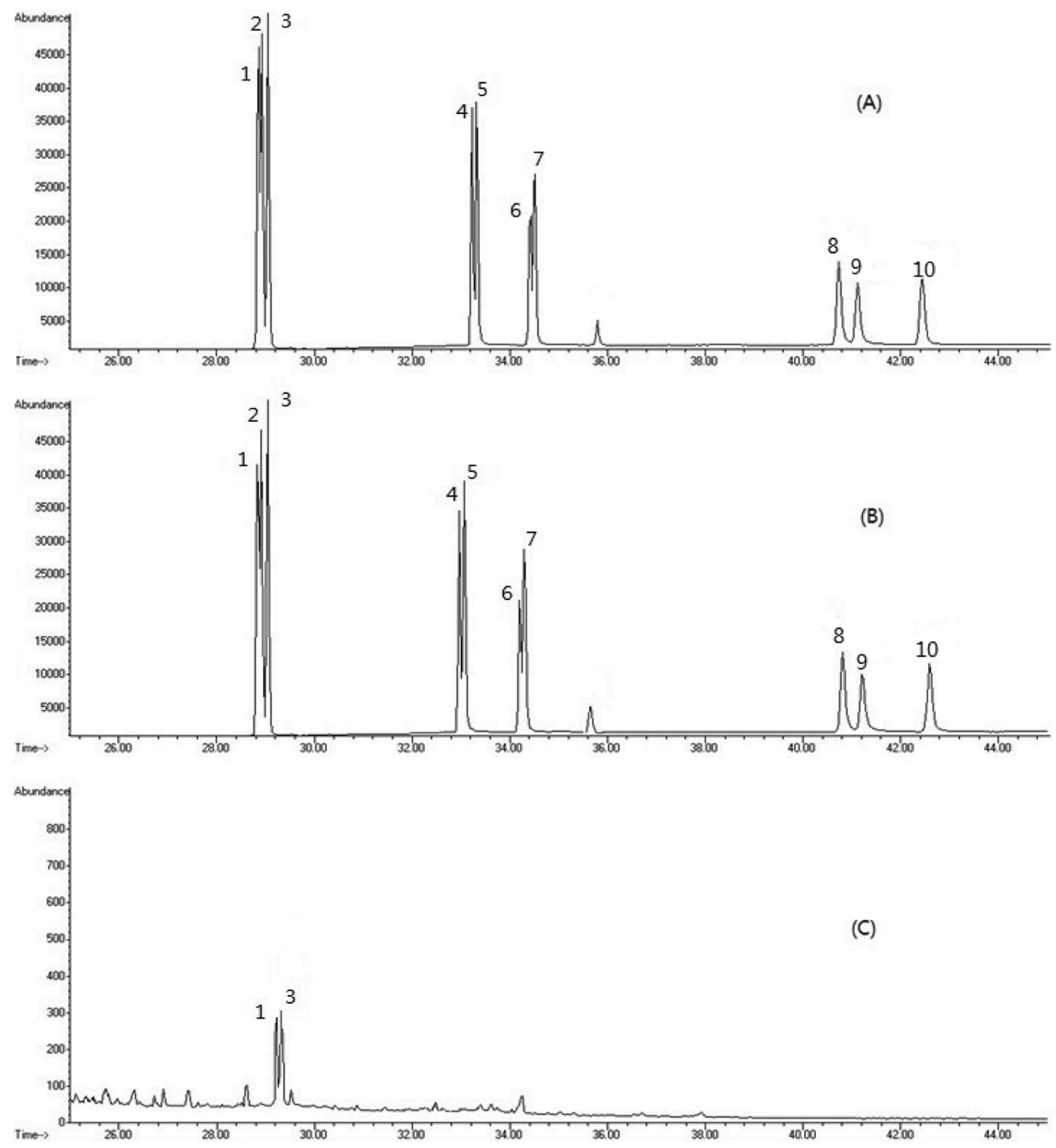

Fig. 1. GC/MS chromatograms of $8 \mathrm{PAH}$ standards $(100 \mu \mathrm{g} / \mathrm{kg})(\mathrm{A}), 100 \mu \mathrm{g} / \mathrm{kg}$ standard spiked sample (B) and BaA, CHR peak in sample (C) 1, benzo[a]anthracene; 2, chrysene-deuterium12; 3, chrysene; 4, benzo[b]fluoranthene; 5, benzo[k]fluoranthene; 6; benzo[a]pyrene-deuterium 12; 7, benzo[a]pyrene; 8 , dibenzo [a,h] anthracene; 9 , benzo[g,h,i]perylene; 10, indeno[1,2,3-c,d]pyrene.

Table 3. LOD, LOQ and recovery of 8 PAHs

\begin{tabular}{|c|c|c|c|c|c|c|c|c|}
\hline \multirow[b]{2}{*}{ PAHs } & \multicolumn{4}{|c|}{ Seafood } & \multicolumn{4}{|c|}{ Dairy product } \\
\hline & $\begin{array}{c}\text { LOD } \\
(\mu \mathrm{g} / \mathrm{kg})\end{array}$ & $\begin{array}{c}\text { LOQ } \\
(\mu \mathrm{g} / \mathrm{kg})\end{array}$ & $\begin{array}{c}\text { Recovery } \\
(\%)^{1)}\end{array}$ & $\begin{array}{l}\text { RSD } \\
(\%)^{1)} \\
\end{array}$ & $\begin{array}{c}\text { LOD } \\
(\mu \mathrm{g} / \mathrm{kg})\end{array}$ & $\begin{array}{c}\text { LOQ } \\
(\mu \mathrm{g} / \mathrm{kg})\end{array}$ & $\begin{array}{c}\text { Recovery } \\
(\%)\end{array}$ & $\begin{array}{c}\text { RSD } \\
(\%)\end{array}$ \\
\hline Benzo $[a]$ anthracene & 0.12 & 0.36 & 103.57 & 14.36 & 0.18 & 0.55 & 102.67 & 12.44 \\
\hline Chrysene & 0.14 & 0.44 & 98.94 & 8.08 & 0.19 & 0.56 & 92.15 & 10.59 \\
\hline Benzo $[b]$ fluoranthene & 0.18 & 0.54 & 92.44 & 12.90 & 0.20 & 0.60 & 96.09 & 13.26 \\
\hline Benzo $[k]$ fluoranthene & 0.20 & 0.60 & 90.99 & 12.10 & 0.04 & 0.12 & 86.87 & 6.75 \\
\hline Benzo $[a]$ pyrene & 0.12 & 0.37 & 98.98 & 13.75 & 0.19 & 0.57 & 90.43 & 13.26 \\
\hline Dibenzo[$[a, h]$ anthracene & 0.20 & 0.61 & 94.72 & 13.43 & 0.10 & 0.30 & 97.15 & 12.95 \\
\hline Benzo $[g, h, i]$ perylene & 0.20 & 0.60 & 93.99 & 13.79 & 0.16 & 0.48 & 93.31 & 9.34 \\
\hline Indeno[1,2,3-c,d]pyrene & 0.19 & 0.58 & 95.95 & 15.31 & 0.13 & 0.40 & 90.75 & 12.59 \\
\hline
\end{tabular}

${ }^{11}$ Average recovery and relative standard deviation of three different concentrations for spiked samples. 
Table 4. Comparison of accuracy and precision (CV) of the polycyclic aromatic hydrocarbons (PAHs)

\begin{tabular}{|c|c|c|c|c|c|}
\hline \multirow{2}{*}{\multicolumn{2}{|c|}{ PAHs }} & \multicolumn{2}{|c|}{ Intraday $(n=3)$} & \multicolumn{2}{|c|}{ Interday $(\mathrm{n}=3)$} \\
\hline & & $\begin{array}{c}\text { Accuracy } \\
(\%)^{1)}\end{array}$ & $\begin{array}{l}\mathrm{CV} \\
(\%)^{2)}\end{array}$ & $\begin{array}{c}\text { Accuracy } \\
(\%)\end{array}$ & $\begin{array}{l}\mathrm{CV} \\
(\%)\end{array}$ \\
\hline \multirow{8}{*}{ Seafood } & $\mathrm{BaA}$ & 116.03 & 5.57 & 115.66 & 1.79 \\
\hline & CHR & 108.85 & 5.55 & 109.43 & 1.64 \\
\hline & $\mathrm{BbF}$ & 104.21 & 1.72 & 104.50 & 1.59 \\
\hline & $\mathrm{BkF}$ & 97.30 & 3.43 & 95.80 & 2.13 \\
\hline & $\mathrm{BaP}$ & 104.35 & 1.85 & 105.09 & 2.44 \\
\hline & DahA & 114.81 & 3.47 & 114.29 & 2.28 \\
\hline & BghiP & 103.44 & 0.81 & 103.95 & 0.94 \\
\hline & IcdP & 113.10 & 3.46 & 111.57 & 2.13 \\
\hline \multirow{8}{*}{$\begin{array}{c}\text { Dairy } \\
\text { product }\end{array}$} & $\mathrm{BaA}$ & 100.33 & 3.19 & 99.70 & 2.02 \\
\hline & CHR & 90.63 & 2.93 & 90.83 & 0.38 \\
\hline & $\mathrm{BbF}$ & 93.78 & 2.37 & 89.28 & 5.21 \\
\hline & $\mathrm{BkF}$ & 95.89 & 2.96 & 97.84 & 0.49 \\
\hline & $\mathrm{BaP}$ & 92.10 & 3.18 & 88.97 & 3.96 \\
\hline & DahA & 95.59 & 3.51 & 98.33 & 0.62 \\
\hline & BghiP & 95.42 & 3.44 & 96.36 & 1.96 \\
\hline & IcdP & 96.13 & 3.32 & 98.53 & 1.81 \\
\hline
\end{tabular}

${ }^{11}$ Accuracy $(\%)=[1-($ mean concentration measured $) /$ concentration spiked] $\times 100$, Accuracy shown as average of each accuracy value of five different concentrations for spiked samples.

${ }^{2)} \mathrm{CV}$ (Coefficient of variation, \%) $=($ S.D. $/$ mean $) \times 100$, Precision shown as average of each precision value of five different concentrations for spiked samples.

in Table 6. Among seafood samples, the highest $\mathrm{BaP}$ concentration in sea eel and the highest total PAHs concentration in Gray mullet. Among dairy product samples, concentration of $\mathrm{BaP}$ was the highest in coffee cream and concentration of total PAHs was the highest in whipping cream.
DouAbul et al. revealed levels of PAHs in edible muscle of fishes collected from the Red Sea. Mean concentrations for individual PAHs in fish were; $\mathrm{BaA} 0.4$, CHR 1.9, BbF $0.5, \mathrm{BkF} 0.5, \mathrm{BaP} 0.5$, and IcdP $0.1 \mu \mathrm{g} / \mathrm{kg}$ dry weight respectively (14).

Dhananjayan and Muralidharan investigates the concentrations of 15 PAHs in 5 species of fish samples collected the Harbour, Mumbai. The levels of 6 carcinogenic PAHs (BaA, BbF, BkF, BaP, IcdP, DahA) ranged from 9.49 to $31.23 \mu \mathrm{g} / \mathrm{kg}$ and the maximum concentration of 15PAHs in marine fish species was found in Goldspotted grenadier anchovy (70.44 $\mu \mathrm{g} / \mathrm{kg}$ wet wt.) (15).

Lawrence and Weber has studied determination of PAHs in dairy product samples collected from local outlets in Canada. The concentration of 5 PAHs (BaA, BbF, BaP, DahA, IcdP) ranged from ND to $1.9 \mu \mathrm{g} / \mathrm{kg}$, in skim milk samples and $7.8 \mu \mathrm{g} / \mathrm{kg}$ in infant formula sample (16). Cho and Shin carried out evaluation of the contents of the 7 PAHs in infant formulas and mixed milk powder. The concentration of 7 PAHs ranged from $0.064 \sim 0.968 \mu \mathrm{g} / \mathrm{kg}$ in the infant formula group and $0.244 \sim 0.775 \mu \mathrm{g} / \mathrm{kg}$ in mixed milk powder samples (17).

It is known that PAHs can be produced during drying processes in direct heating (18). Whereas Aguinaga et al. reported that no PAHs was detected in the half-fat milk and skimmed milk samples, perhaps since PAHs are reduced during the skimming process (19).

According to the Commission Regulation (EC) No. 1881/ 2006, the maximum tolerance limit for $\mathrm{BaP}$ of infant formula, follow-on formula, and baby foods is $1 \mu \mathrm{g} / \mathrm{kg}$ (5). In this study, no sample exceeded the maximum permitted level of $1 \mu \mathrm{g} / \mathrm{kg}$.

The main aim of the present work is to evaluate an ana-

Table 5. Concentration of polycyclic aromatic hydrocarbons (PAHs) in seafood ( $\mu \mathrm{g} / \mathrm{kg}$ )

\begin{tabular}{|c|c|c|c|c|c|c|c|c|c|}
\hline \multirow{2}{*}{ Food category } & \multicolumn{9}{|c|}{ PAHs $(\mu \mathrm{g} / \mathrm{kg})$} \\
\hline & $\mathrm{BaA}$ & CHR & $\mathrm{BkF}$ & $\mathrm{BbF}$ & $\mathrm{BaP}$ & IcdP & BghiP & DahA & Total PAHs \\
\hline Tuna & $0.18 \pm 0.03$ & ND & $0.24 \pm 0.02$ & ND & $0.35 \pm 0.02$ & $0.30 \pm 0.02$ & ND & ND & $1.06 \pm 0.08$ \\
\hline Flounder & $0.20 \pm 0.02$ & ND & $0.22 \pm 0.02$ & ND & $0.21 \pm 0.01$ & $0.21 \pm 0.02$ & ND & ND & $0.84 \pm 0.05$ \\
\hline Sea bream & $0.26 \pm 0.02$ & ND & $0.25 \pm 0.04$ & ND & $0.33 \pm 0.02$ & $0.30 \pm 0.01$ & ND & ND & $1.15 \pm 0.08$ \\
\hline Pomfret & $0.30 \pm 0.04$ & ND & ND & $0.24 \pm 0.03$ & $0.34 \pm 0.03$ & $0.28 \pm 0.03$ & ND & ND & $1.17 \pm 0.11$ \\
\hline Gopher & $0.41 \pm 0.02$ & ND & $0.34 \pm 0.00$ & ND & $0.47 \pm 0.03$ & $0.25 \pm 0.02$ & ND & $0.57 \pm 0.02$ & $2.03 \pm 0.06$ \\
\hline Gray mullet & $0.42 \pm 0.03$ & ND & ND & $0.24 \pm 0.02$ & $0.38 \pm 0.03$ & $0.30 \pm 0.02$ & ND & $0.59 \pm 0.04$ & $1.94 \pm 0.12$ \\
\hline Spoon worm & $0.20 \pm 0.02$ & ND & ND & ND & $0.24 \pm 0.03$ & ND & ND & ND & $0.44 \pm 0.04$ \\
\hline Sea squirt & $0.14 \pm 0.01$ & ND & ND & ND & $0.22 \pm 0.02$ & ND & ND & ND & $0.36 \pm 0.04$ \\
\hline Styela clava & ND & ND & ND & ND & $0.39 \pm 0.04$ & ND & ND & ND & $0.39 \pm 0.04$ \\
\hline Manila clam & $0.23 \pm 0.03$ & ND & $0.31 \pm 0.01$ & ND & $0.24 \pm 0.03$ & ND & ND & $0.37 \pm 0.01$ & $1.14 \pm 0.04$ \\
\hline Freshwater eel & $0.36 \pm 0.03$ & ND & ND & ND & $0.45 \pm 0.03$ & ND & ND & ND & $0.81 \pm 0.05$ \\
\hline Corbicula & $0.28 \pm 0.01$ & ND & $0.30 \pm 0.03$ & ND & $0.29 \pm 0.04$ & $0.23 \pm 0.02$ & ND & ND & $1.10 \pm 0.08$ \\
\hline Sea eel & $0.42 \pm 0.02$ & ND & ND & ND & $0.57 \pm 0.03$ & ND & ND & ND & $0.99 \pm 0.05$ \\
\hline Webfoot octopus & $0.29 \pm 0.02$ & ND & ND & $0.24 \pm 0.03$ & $0.40 \pm 0.03$ & ND & ND & $0.21 \pm 0.01$ & $1.15 \pm 0.08$ \\
\hline Pen shell & $0.30 \pm 0.02$ & $0.15 \pm 0.01$ & $0.36 \pm 0.04$ & ND & $0.25 \pm 0.02$ & ND & ND & $0.25 \pm 0.03$ & $1.31 \pm 0.10$ \\
\hline
\end{tabular}

All treatments were replicated 3 times and represented means \pm standard deviations.

$\mathrm{ND}=$ not detected, below limit of detection. 
Table 6. Concentration of PAHs in dairy products $(\mu \mathrm{g} / \mathrm{kg})$

\begin{tabular}{|c|c|c|c|c|c|c|c|c|c|}
\hline \multirow{2}{*}{ Food category } & \multicolumn{9}{|c|}{ PAHs ( $\mu \mathrm{g} / \mathrm{kg})$} \\
\hline & $\mathrm{BaA}$ & CHR & $\mathrm{BkF}$ & $\mathrm{BbF}$ & $\mathrm{BaP}$ & IcdP & BghiP & DahA & Total PAHs \\
\hline Low-fat milk & ND & ND & ND & ND & ND & ND & ND & ND & ND \\
\hline Process milk & ND & ND & ND & ND & ND & ND & ND & ND & ND \\
\hline Icecream cone & $0.26 \pm 0.01$ & $0.24 \pm 0.02$ & ND & ND & ND & ND & $0.18 \pm 0.01$ & ND & $0.68 \pm 0.04$ \\
\hline Cup icecream & $0.23 \pm 0.01$ & ND & ND & ND & ND & ND & ND & ND & $0.23 \pm 0.01$ \\
\hline Lactic beverage & ND & ND & ND & ND & ND & ND & ND & ND & ND \\
\hline Semisolid yoghurt & ND & ND & ND & ND & ND & ND & ND & ND & ND \\
\hline Liquid yoghurt & ND & ND & ND & ND & ND & ND & ND & ND & ND \\
\hline Cheese & $0.28 \pm 0.02$ & ND & $0.09 \pm 0.01$ & $0.34 \pm 0.03$ & $0.24 \pm 0.01$ & ND & $0.22 \pm 0.02$ & $0.21 \pm 0.01$ & $1.38 \pm 0.09$ \\
\hline Mozzarella cheese & $0.23 \pm 0.01$ & ND & $0.08 \pm 0.01$ & ND & $0.22 \pm 0.01$ & ND & $0.21 \pm 0.01$ & $0.21 \pm 0.01$ & $0.94 \pm 0.06$ \\
\hline Whipping cream & $0.42 \pm 0.02$ & $0.28 \pm 0.02$ & $0.27 \pm 0.02$ & $0.90 \pm 0.06$ & $0.56 \pm 0.03$ & $0.19 \pm 0.01$ & $0.56 \pm 0.03$ & ND & $3.17 \pm 0.19$ \\
\hline Coffee cream & $0.40 \pm 0.02$ & $0.28 \pm 0.03$ & $0.27 \pm 0.02$ & $0.87 \pm 0.05$ & $0.56 \pm 0.03$ & $0.21 \pm 0.01$ & $0.57 \pm 0.04$ & ND & $3.16 \pm 0.19$ \\
\hline Stick ice cream & $0.30 \pm 0.02$ & $0.34 \pm 0.02$ & $0.08 \pm 0.01$ & $0.27 \pm 0.02$ & $0.23 \pm 0.01$ & ND & $0.25 \pm 0.02$ & $0.19 \pm 0.01$ & $1.66 \pm 0.11$ \\
\hline Monaka ice cream & $0.27 \pm 0.01$ & $0.34 \pm 0.02$ & ND & ND & ND & ND & $0.22 \pm 0.02$ & ND & $0.83 \pm 0.05$ \\
\hline Condensed milk & $0.29 \pm 0.02$ & $0.25 \pm 0.02$ & $0.08 \pm 0.01$ & $0.31 \pm 0.03$ & $0.24 \pm 0.01$ & ND & $0.29 \pm 0.02$ & $0.21 \pm 0.01$ & $1.66 \pm 0.11$ \\
\hline Milk & ND & ND & ND & ND & ND & ND & ND & ND & ND \\
\hline
\end{tabular}

All treatments were replicated 3 times and represented means \pm standard deviations.

$\mathrm{ND}=$ not detected, below limit of detection.

lytical method for the determination of 8 PAHs and the content of carcinogenic PAHs including $\mathrm{BaA}, \mathrm{CHR}, \mathrm{BbF}, \mathrm{BkF}$, $\mathrm{BaP}$, DahA, BghiP and IcdP in milk products and seafood using the GC/MS. In this way, the results of PAHs concentration can be used to select those contributing to minimize their presence, and to establish the limits of PAHs in this kind of food products.

\section{ACKNOWLEDGEMENT}

This research was supported by a grant (13162MFDS049) from Ministry of Food and Drug Safety in 2013-2015.

\section{REFERENCES}

1. Lawrence, J.F. and Weber, D.F. (1984) Determination of polycyclic aromatic hydrocarbons in some Canadian commercial fish, shellfish, and meat products by liquid chromatography with confirmation by capillary gas chromatography-mass spectrometry. J. Agric. Food Chem., 32, 789-794.

2. Hodgeson, J.W., Bashe, W.J. and Baker, T.V. (1990) Determination of polycyclic aromatic hydrocarbons in drinking water by liquid-liquid extraction and HPLC with coupled ultraviolet and fluorescence detection. EPA Method 550.1. US Environmental Protection Agency, USA.

3. IARC. (1987) IARC Monographs on the evaluation of carcinogenic risks to humans. Overall evaluations of carcinogenicity: an updating of IARC Monographs. International Agency for Research on Cancer, Lyon, France. pp. 1-440.

4. IARC. (2010) IARC Monographs on the evaluation of carcinogenic risks to humans. Some non-heterocyclic polycyclic aromatic hydrocarbons and some related exposures. IARC, 92, $1-853$.

5. EC. (2006) Commission regulation (EC) No.1881/2006 of 19
December 2006 setting maximum levels for certain contaminants in foodstuffs. Off. J. Eur. Union, L364, 365-323.

6. EFSA. (2008) Polycyclic aromatic hydrocarbons in food. Scientific opinion of the panel on contaminants in the food chain. EFSA J., 724, 1-114.

7. EFSA. (2008) Findings of the EFSA data collection on polycyclicaromatichydrocarbons in food. EFSA, Parma, pp. 1-55.

8. Wretling, S., Eriksson, A., Eskhult, G.A. and Larsson, B. (2010) Polycyclic aromatic hydrocarbons (PAHs) in Swedish smoked meat and fish. J. Food Compos. Anal., 23, 264-272.

9. Harvey, G.R. (1998) Environmental chemistry of PAHs. In: the handbook of environmental (Alasdair, H., Neilson, ed.). Springer, Berlin, pp. 2-10.

10. Kobayashi, R., Cahill, T.M., Okamoto, R.A., Maddalena, R.L. and Kado, N.Y. (2007) Controlled exposure chamber study of uptake and clearance of airborne polycyclic aromatic hydrocarbons by wheat grain environ. Environ. Sci. Technol., 41, 7934-7940.

11. Alomirach, H., Al-Zenki, S., Al-Hooti, S., Zaghloul, S., Sawaya, W., Ahmed, N. and Kannan, K. (2011) Concentrations and dietary exposure to polycyclic aromatic hydrocarbons (PAHs) from grilled and smoked foods. Food Control, 22, 2028-2035.

12. Rey-Salgueiro, L., García-Falcón, M.S., Marínez-Carballo, E. and Simal-Gándara, J. (2008) Effects of toasting procedures on the levels of polycyclic aromatic hydrocarbons in toasted bread. Food Chem., 108, 607-615.

13. Wenzl, T., Simon, R., Anklam, E. and Kleiner, J. (2006) Analytical methods for polycyclic aromatic hydrocarbons (PAHs) in food and the environment needed for new food legislation in the European Union. TrAC Trends Anal. Chem., 25, 716725 .

14. DouAbul, A.A.Z., Heba, H.M.A. and Fareed, K.H. (1997) Polynuclear aromatic hydrocarbons (PAHs) in fish fromthe red sea coast of yemen. Hydrobiologia, 352, 251-262.

15. Dhananjayan, V. and Muralidharan, S. (2012) Polycyclic aro- 
matic hydrocarbons in various species of fishes from mumbai harbour, India, and their dietary intake concentration to human. Int. J. Oceanogr., 2012, 1-6.

16. Lawrence, J.F. and Weber, D.F. (1984) Determination of polycyclic aromatic hydrocarbons in Canadian samples of processed vegetable and dairy products by liquid chromatography with fluorescence detection. J. Agric. Food Chem., 32, 794797.

17. Cho, H.K. and Shin, H.S. (2012) Evaluation of polycyclic aromatic hydrocarbon contents and risk assessment for infant for- mula in Korea. Food Sci. Biotechnol., 21, 1329-1334.

18. Rohrlich, M. and Suckow, P. (1970) Untersuchungen uber 3,4benzypyren in getreide und getreidemahlprodukten. Getreide Mehl, 20, 90-93.

19. Aguinaga, N., Campillo, N., Vinas, P. and Hernández-Córdoba, M. (2007) Determination of 16 polycyclic aromatic hydrocarbons in milk and related products using solid-phase microextraction coupled to gas chromatography-mass spectrometry. Anal. Chim. Acta, 596, 285-290. 